\title{
Online Social Work Practice: Issues and Guidelines for the Profession
}

\author{
Goutham M. Menon \\ Julie Miller-Cribbs
}

\begin{abstract}
Therehas been growth in the utilization of information and communication (ICT) toolsin thefied d of social work in recent years. Whilemost of thework has revolved around community practice, some social workers have moved into the realm of online, web-based therapeutic practice. This paper discusses important issues emerging from this new form of social work practiceand concludes with suggested guidelines for the use of ICTs in social work practice.
\end{abstract}

Keywords: Web-based counseling, onlinetherapy, technology-enhanced practice

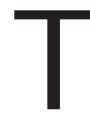

he profession of social work has witnessed a growth in the creative use of technology in various areas of professional work for many decades (Finn \& Lavitt, 1994; Finn, 1995; Shyne, 1954). Ranging from telephone support groups (Kennard \& Shilman, 1979; Meier, Galinsky \& Rounds, 1995; Roffman, Beadnell, Ryan \& Downey, 1995; Rounds, Galinsky \& Stevens, 1991; Wiener, Spencer, Davidson \& Fair, 1993) to the more recent exploration of computer-based applications in human services (Finn, 1995; Finn \& Lavitt, 1994; Smyth \& Harris, 1993; Weinberg, Uken, Schmale \& Adamek, 1995; Stofle, 1997), professional practice with individuals, families, and groups has seen the influence of emerging information and communication technologies (ICT). ICTs have also influenced the field of community practice in positive ways (Downing, Fasano, Friedland, McCullough, Mizrahi \& Shapiro, 1991; McNutt, 2000), especially in the area of electronic advocacy (Bennett \& Fielding, 1999; Boland, 1998; Buck, 1996; Fitzgerald \& McNutt, 1999; McNutt \& Boland, 1988; 1999; Menon, 2002; 2000c).

While most of the utilization of technology falls into the area of helping groups and communities, social work is beginning to see a growing interest in the provision of online counseling and therapeutic services for individuals (Cutter, 1996; Grohol, 1997; Levenson, 1997; Sampson, Kolodinsky \& Greeno, 1997). Some of these professionals offer such services alone or as part of a group of practitioners ${ }^{1}$. As students and practitioners become more familiar with technology-based appli-

Goutham M. Menon, Ph.D. is Assistant Professor \& Director, Center for Technology in Social Work Education and Practice, College of Social Work, University of South Carolina, Columbia, SC 29208. Julie Miller-Cribbs, Ph.D. is Assistant Professor, College of Social Work, University of South Carolina, Columbia, SC 29208. 
cations (either on their own or through education), it is probable that the use of ICT for counseling will become more prevalent.

Professional organizations in fields similar to social work have begun to address the issue of online counseling. For example, the American Psychological Association (APA) and the medical field, particularly psychiatry, has begun to address ethical issues associated with the delivery of services online (see APA, 1997; American Medical Informatics Association, 1998). The National Board of Certified Counselors (NBCC) purports to “... create standard definitions of technology-assisted distance counseling that can be easily updated in response to evolutions in technology and practice" (NBCC, 2001) and the American Counseling Association (ACA) approved ethical standards for Internet and on-line counseling in 1999 (ACA, 1999). Internet Healthcare Coalition (IHC), an organization that attempts to set high standards for the distribution of health information via the Internet, has developed a set of ethical guidelines relevant to our profession (IHC, 2000). Finally, the International Society for Mental Health Online(ISMHO) has also developed guidelines for the practice of online counseling, though these are not specific to social work (ISMHO, 2000).

Despite this continued and expanded use of ICT in the field of social work, the profession currently has no established guidelines for the practice of social work online. Many individuals and organizations have begun to address issues related to the online practice of social work, citing possible advantages and disadvantages of such practice and occasionally providing some general guidelines for online practice (Coleman, 2000; Levenson, 1997; Stofle, 1997). Stofle(2001), a social worker, has written a book about choosing an online therapist; yet, this book is geared towards potential consumers, not practitioners. Finally, it was noted by Powell (1998) that while the NASW Insurance Trust mentions that social workers who practice online are covered for malpractice, they express concern about the issue of online practice.

Some social work organizations, such as the Clinical Social Work Federation (CSWF), have also argued strongly against the use of online counseling:

"So much human suffering has been caused by disconnection-disconnection between individuals, between thought and feeling, between body and mind-and e-therapy offers yet another form. Clients seek our services in order to improve the quality of their lives, the quality of their relationships. Alienation from others and the self will not be healed through a virtual connection in cyberspace, a 'connection' that is fraught with risks and hazards for both clients and clinicians." (CSWF, 2001)

Despite CSWF's position, social workers currently provide online services and are likely to continue doing so. It is the contention of the authors of this paper that simple warnings about the dangers of online therapy or broad ethical discussions of this new modality of practice are not enough to protect our clients and practitioners, alike. There is clearly a need for the profession to step up and lead a debate culminating in specific guidelines for practice that helpsto regulate the profession in virtual therapeutic and supportive environments. 
The current practice of online counseling has heightened the need for the social work profession to seriously examine this avenue of service delivery. To expand this endeavor, this paper explores and highlights the important issues related to this area of social work practice. It will conclude by providing suggested guidelines for the practice of online social work.

\section{DEFINING ONLINE THERAPY}

Computer-mediated communication (CMC) is frequently thought of in terms of technology only, thus, many often assume that CMC is simply about receiving and exchanging information (December, 1997). However, it has been argued that CMC is "a process of human communication via computers, involving people, situated in particular contexts, engaging in processes to shape media for a variety of purposes" (December, 1997). ${ }^{2}$ We know that social work communication in faceto-face settings involves the use of communication to bring about change. Online therapy is just one form of $\mathrm{CMC}$, one that obviously involves more than simple information exchange.

Bloom (1998) defines webcounseling " as "the practice of professional counseling that occurs when client and counselor are in separate or remote locations and utilize electronic means to communicate with each other" (p. 21). Obviously, this definition is fairly basic, including only the "context" of practice in the definition. Perhaps a definition adopted by King and Moreggi (1998) would be more inclusive and holistic. They define "behavioral tele-health" as “... all forms of synchronous and asynchronous Internet mental health efforts, where the stated goal is the establishment of some form of therapeutic contact" (p. 93). CMC can also be referred to as the creation and dissemination of meaning; through various mechanisms (e-mail, chat, web sites), the perception of meaning, and the participation in "forums for communication that begin to exhibit characteristics of community-including a shared sense of purpose, norms for behavior, and traditions" (December, 1997).

Distinguishing between the simple provision of information versus the communication and perception of meaning is particularly salient for social work. There are a wide range of services being provided online, ranging from the provision of information to the actual provision of social work services. Often, the terms used to describe these services are used interchangeably and, thus, provoke a misunderstanding as to the nature of services provided. For example, sometimes, online counseling services are simply informational services. At such websites the client has an opportunity to request information or ask a question related to a specific problem area. This is analogous to the many "help" columns seen in popular newspapers and magazines. Sometimes, the individual pays for the e-mail response that he or she receives for the question posed.

Another type of service is what is commonly known as "online therapy." The goal of online therapy is to provide a long-term therapeutic relationship. Such a service involves individual-therapist communication using electronic mail, chat rooms, instant messaging, and other tools over a protracted period of time. Such services aim to build rapport and providefor an ongoing therapeutic relationship. This paper largely focuses on the second kind of service, online therapy. For pur- 
poses of this paper, we will define on-line therapy as the provision of therapeutic services utilizing Internet applications, both text-based and audio/video, which enable clients to receive services without real face-to-face contacts with the provider (Menon \& Miller-Cribbs, 2001).

There are major issues related to providing online therapy that must be addressed by the field of social work (Menon, 1998a/ b; 2000a/ b; 2001; Menon \& Miller-Cribbs, 2001). The following is a discussion of important issues related to providing online therapy by social workers: the issue of face-to-face contacts, anonymity, technical aspects of the provision of the service, legal issues, licensing and cross border practice, and evaluation of online therapy.

Face to-Face: Is It Better? Is It Necessary?

The inability of a social worker to assess non-verbal cues online is an area that concerns many in the profession (Coleman, 2000). Thus, social workers are pressed to think about why face-to-face contact is preferable and highlight ways in which therapy can be conducted without non-verbal cues. Can warmth, caring, and compassion be conveyed via text? How should social workers account for the absence of non-verbal communication?

Therapy essentially involves an ongoing therapeutic relationship between two people who meet face-to-face. The therapist establishes trust and rapport with clients through this relationship. Often, non-verbal communication is as important as verbal communication. Online, it may be more difficult to establish trust and rapport since face-to-face contact is unavailable and the subsequent utilization of non-verbal cues becomes impossible.

However, others have argued that face-to-face communication is not necessarily the most ideal type of therapy for all clients and their problems. Walther (1996) argues that when a therapist has freedom from the social responsibilities of "looking interested," then, he or she is able to take the time to thoughtfully respond in terms of selecting the right words and message. Furthermore, the time delay between messages forces individuals to think about what they send prior to communicating their feelings.

There are also some possibilities for mimicking non-verbal cues using the keyboard. For example, Internet-based communication is filled with the usage of acronyms and emoticons (emotional icons, such as :) happy face ;( crying sadly, etc.). ${ }^{3}$ One possibility is to develop a set of standardized emoticons and acronyms to capture the feelings of the client at any given point in time. These could be tailored into the software utilized for online practice. Alternatively, an online therapist could provide clients with a sheet of "emoticons," so that the client could incorporate these during sessions with the therapist.

Some of the issues listed above may be addressed once social workers have faster access to the Internet through broadband Internet-video technology. Broadband, either through DSL connections or by cable TV providers, may allow practitioners to have computer-based video conferencing options. This will enable social work practitioners to have adequate visual access to clients. However, until then, one must expect poor quality video/audio streams when 
using telephone lines. Currently, the majority of the population who have Internet access utilize modems to dial-up in speeds ranging from $28.8 \mathrm{~K}$ to $56 \mathrm{~K}$ using regular analog phone lines. In some sectors of the country, we are also seeing an increase in DSL linkups. DSL, which stands for Digital Subscriber Line, provides high-speed Internet Access using regular telephone lines. It has the ability to move data over the phone lines at speeds up to $6 \mathrm{M} \mathrm{b} / \mathrm{s}$ (six million bits per second) or 140 times quicker than the fastest analog modems available today (56,000 bits per second). In addition to its high speed, DSL has many benefits over analog connections. Unlike dial-up connections that require analog modems to "dial-in" to the Internet Service Provider every time the user wants to retrieve email or obtain access to the Internet, DSL connections are always on. That means no more logging on and off, no more busy signals, and no more waiting for the connection to happen. Another benefit is the ability to use the telephone while accessing the Internet and not having to choose between the two.

TheCloak of Anonymity-A Good or Bad Thing?

There is a growing body of literature that attempts to disentangle the concerns around intimacy and nonverbal communication (Burgoon, Buller \& Woodall, 1989; Cherny, 1995; Guerrero, DeVito \& Hecht, 1999; Patterson, 1983; 1990). Furthermore, there are greater philosophical conversations conducted regarding the meaning of intimacy and self-disclosure (Walther, 1996). In fact, Lerner's (1990) definition of intimacy reveals little about the necessity for face-to-face contact in establishing intimacy as she notes:

For starters, intimacy means that we can be who we are in a relationship, and allow the other person to do the same. "Being who we are" requires that we can talk openly about things that are important to us, that we take a clear position on where we stand on important emotional issues, and that we clarify the limits of what is acceptable and tolerable to us in a relationship. "Allowing the other person to do the same" means that we can stay emotionally connected to that other party who thinks, feels, and believes differently, without needing to change, convince, or fix the other. An intimate relationship is one in which neither party silences, sacrifices, or betrays the self and each party expresses strength and vulnerability, weakness and competence in a balanced way." (p. 3)

Others have argued that the lack of face-to-face contact can be a positive feature when working with certain clients. In some cases, the anonymity that faceless interaction provides could have certain advantages, such as higher levels of self-disclosure, more intimacy, heightened self-expression, and stigma management (Cohen \& Kerr, 1998). People who are reluctant to seek out counseling in a traditional setting may be more willing to seek out an online counselor.

Thus, online counseling may be a viable method of service delivery for certain client groups and problems. The telephone, for example, has been a long established and accepted mode for delivering crisis intervention services. As Cohen \& Kerr (1998) note, "While clients with strong needs for emotional support may find the reduced cues environment a poor substitute for face-to-face interaction, computer-mediated counseling may be a viable option for more independent 
people dealing with specific problems or those interested in personal growth" ( $p$. 24). Stofle (2001) addresses the issue of the appropriateness of online counseling in his conceptualization of "Levels of Care and Online Therapy" continuum. He refers to varying levels of intensity of treatment that need to match the intensity of the client's problem. He places online therapy on the lower intensity side of the level of care continuum and, so, it is best used for issues/problems that are low intensity, as well. Such a conceptualization is hel pful in determining the uses and possibilities of online therapy by social workers. The profession of social work should carefully consider what kinds of problems and issues are best suited for online delivery and establish guidelines for the delivery of such services.

The provision of anonymity is both a strength and weakness of online social work practice. Often, particularly in small communities, people know where the therapists live or practice, so by simply parking a car in a certain place, an individual risks being "found out." These risks are not as apparent with online counseling. This could be especially beneficial for those individuals who seek help but are too embarrassed to go to a social worker's office.

Online practice also has the potential to limit or eliminate biases that can corrupt treatment and slow the rapport-building process. In this way, the Internet can be seen as a social leveler (Levenson, 1997). Age, gender, ethnicity, race, national origin, and other demographic features that provoke bias are absent. The client is a "faceless" individual and, thus, therapist and client bias are held in check. Some authors have stated that the "faceless" nature of counseling might, in fact, improve the chances of certain reluctant individuals seeking treatment (Cohen \& Kerr, 1998). Under the cloak of supposed anonymity, certain people might actively take part in therapy sessions. It might allow some to be more open about the problems they face and not be embarrassed to talk about them.

Technical Aspects: Hardware, Software, and Skills for Social Workers and Clients

The utilization of technology for counseling has its inherent technological problems. Typically, web-based therapies are conducted through the client-side computer, the therapist-side computer, and the servers that connect the two. Furthermore, depending on the nature of the counseling session, somewhere between two and six software programs are used (see Table 1). Adding hardware and software into the practice repertoire creates some noteworthy salient issues. Social workers who practice online are ultimately responsible for protecting data (Levenson, 1997) as well as ensuring that they have the technical skills that are requisite for practicing online (Stofle, 1997).

Keeping Data Secure

The most important is data security. The "real world" is replete with reports of data and identity theft either through the improper, unauthorized access to a person's personal computer or through the malicious hacking of server or network traffic. In a review of websites conducted by the authors, it was disheartening to note that many of the mental health professionals who conduct webbased therapy often utilize unsecured servers and almost never use encryption software. 


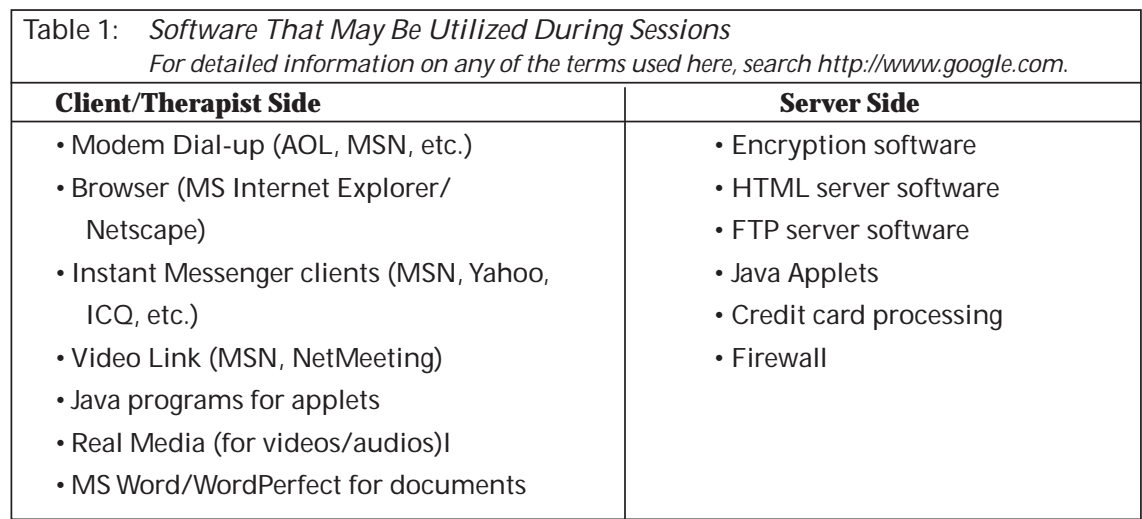

With the growth of software that "snoops," it is also becoming much easier for anyone with malicious intent to load certain software into an unsuspecting client or therapist's computer (see Walker, 8/21/2000). The software, thus, is programmed to "capture" activities on a regular basis. Such an individual is then able to read confidential material and access client files and records.

Protecting health information is a critical social work issue, even beyond the online arena. There are numerous cases regarding the violation of health care information security ${ }^{4}$ that are critical for social workers to be aware of while embarking in virtual practice. For the most part, social workers are unaware of who ultimately has access to their data, particularly electronic data such as e-mail.

\section{Text Residue}

A grave matter in the area of web-based counseling is the issue of reporting and taking down case-related notes. In an online, text-based environment, entire transcripts are recorded which include files that are seemingly "deleted" by the user. In fact, text residue is left behind even if records are deleted from the therapist or client computer. This residue can be resuscitated through the use of widely available data scavenging software. Current convention on recording case notes emphasizes that the social worker record only what is truly important in the case. In a web-based environment, this is not possible. As previously mentioned, protective measures such as encryption can be taken, but it is impossible to remove all the residual effects of communication (unless the hard drive is reformatted). This has legal implications for social workers, as these text-based communications, including electronic mail and other forms of data stored on the computers and servers, could be subpoenaed in court cases. As such, case notes would include the content of entire sessions and the social worker has less control over how the notes are to be interpreted.

For example, if a social worker were conducting a group session using an online chat session, each group member would have a transcript of the group session that could be printed, copied, and distributed to other individuals. Of course, this risk also exists in "live" group sessions, but individual group members do not have access to a printed record. However, the danger of the "printed" record should not be ignored. Clients in violent relationships who receive counseling 
online might become more vulnerable if their text residue, e-mail, or chat information is intercepted.

Of course, there are risks associated with any kind of therapy (on-line or offline) as a result of negligence on the part of the social worker or malicious intent by an individual. However, most can be eliminated by proper use of secured sites and/or encryption software. Encryption ${ }^{5}$ allows the sender and the receiver to scramble and unscramble messages sent through the network. This prevents the data from falling into the wrong hands. Currently, no one is required to utilize such software when they practice online, but such a requirement may be a useful guideline.

\section{Licensing and Cross Border Practice: Who Is Responsible For Whom?}

The "global" nature of online therapy makes the issue of licensing quite complicated. Obviously, ensuring accountability in social work practice is an important aspect of social work. Almost all states have some form of exam and/or the mandatory upgrading of skills through the accumulation of continuing education units. In an online environment, verification of such qualifications becomes more difficult. However, requirements for social work licenses vary from state to state. The licensing boards in each state are free to set their own standards and require practitioners to abide by them. Furthermore, most licenses have limited portability. State differences in licensing and portability issues make agreement on national standards for online counseling difficult. Social workers providing services to individuals in countries other than the U.S. is also an issue that needs to be addressed. Stofle (1997) remarks that online therapists should practice only in states where they are licensed and that a "national certification for online therapists" should be instituted. He further argues that only "experienced therapists" should practice online counseling.

Currently, several online sites provide a service that provides a "credentials check" of therapists. Consumers can go to such sites and retrieve information regarding the education, degree(s), and licensees of registered online therapists. It may be feasi ble to require that social workers register with such services and for the profession to develop some kind of national certification program for those interested in online therapy. To date, no national or state social work organizations have attempted such a service.

\section{Evaluating OnlineSocial Work Practice}

The efficacy of online therapy has not been well studied. Most of the evidence, thus far, has been anecdotal with a few exceptions (Barak, 1999; Barak \& WanderSchwartz, 2002; King \& Moreggi, 1998; Murphy \& Mitchell, 1998). There is an obvious need to conduct empirical studies in order for the social work profession to proceed in this area of practice. The same standards utilized to evaluate face-toface therapy should be applied to online therapy. There are many approaches one could try in order to understand the nature of semantic conversations. Apart from using standardized measures that are typically used in real-life settings, transcripts of online sessions could give way to the potential for rich qualitative and content analysis. It would also be interesting to see what types of theoretical frameworks work best in an online setting. 


\section{CONCLUSIONS}

There is enormous potential for the delivery of online social work practice. ICT can provide services to hard-to-reach clients, as it is geographically accessible and can reach clients in remote areas. Online counseling can be conducted from home, thus, bringing services to homebound individuals or those with limited mobility. ICT can be convenient, perhaps helping busy individuals carve time from their lives to talk to a social worker. From a physical standpoint, online services are a safe way to deliver services. Some people may enjoy the anonymity it provides either because of the issue they would like to discuss or because the community in which they live is small, which compromises their privacy. It may be the best, most cost-effective way to deliver services such as follow-up, referrals, support for relapse prevention, group services, informational services, and case management.

Not much is known regarding the effectiveness of online therapy. In addition, there are a host of possible legal and ethical issues that must be considered. Social work must begin to seriously consider the impact of online therapy on the profession. As previously noted, many social workers are already using these new forms of electronic service delivery without having a set of specific social work guidelines in place. Professional organizations in other fields have begun to take online counseling seriously, to the point of amending the language in their Code of Ethics to reflect on-line therapies. Social work must also develop guidelines for the online practice of social work.

It is suggested that social work consider the following as suggestions for incorporating standards for online therapy into the social work profession:

1. Revise the Code of Ethics to reflect technological innovations, including such issues as:

a. Confidentiality of clients.

b. Providing services via secured and non-secured websites.

c. Transferring information electronically.

d. Securing client records.

e. Identifying best use or a mandatory list of software, particularly encryption.

f. Identifying the scope and boundaries of online practice.

g. Establishing guidelines regarding the types of clients and issues for which online therapy is appropriate.

h. Establishing availability of therapists.

i. Providing limits of confidentiality (as in face-to-face therapy) but also including a discussion of the pros/cons and limits of online counseling.

j. Addressing issues related to professional identification online, perhaps by mandating participation in "credentials check" services or establishing a "National Social Work Credential Check."

k. Addressing issues related to developing social work websites that advertise therapy services. 


\section{NASW tasks}

a. Reflect issues of web-based counseling in the NASW practicestandards.

b. Create a task force to examine the practice of and effectiveness of online therapies.

c. Offer specific technology-based CEUs to online therapists.

d. Limit cross-state/ national borders counseling until liability guide lines are laid out.

3. Other tasks

a. Mandate an intense empirical evaluation of any type of web-based therapy.

b. Generate a list of accredited social work programs and licensed social workers available to potential clients on the web, with a link placed at the bottom of online social workers' web pages.

c. Establish constant credibility/content checks of websites by NASW, CSWE, and other professional bodies.

The Social Work profession must keep pace with the new and emergent tools of practice. Traditional counseling will not "disappear" as these new approaches are adopted; however, poor practice of social work may occur if clear guidelines are not created for those social workers practicing online. Like it or not, social work practice will occur online, and it is up to the profession to ensure that such practice is conducted thoughtfully and ethically. As Stofle (1997) notes, "If the ethical therapist is not online, who is?"

\section{Endnotes}

${ }^{1}$ Metanonia.org provides a list of individuals who provideonline counseling. There are several social workers listed on this site.

${ }^{2}$ For a discussion of scholarly debate on the definitions of Computer-Medicated Communications, refer to CMC Magazine, Volume4, No. 1, 1997 at: http:// www.december.com/cmc/mag/ 1997/jan/december.html.

${ }^{3}$ For information regarding emoticons, refer to: http:// wombat.doc.ic.ac.uk/foldoc/foldoc.cgi ?query=emoticon.

${ }^{4}$ For a list of news articles and resources related to healthcare information security, refer to: http:// www.unh.edu/social-work/SW810/Ethicis.htm.

${ }^{5}$ For details about encryption, refer to NetAction's page: $\underline{\text { http:// www.netaction.org/encrypt/. }}$

\section{References}

American Counseling Association. (1999). Special Section: Ethical standards for internet/on-line counseling. Retrieved December 10, 2001, from: http://www.counseling.org/gc/cybertx.htm.

American Medical Informatics Association. (AMIA). (1998, Jan/Feb). Guidelines for the clinical use of electronic mail with patients. [Electronic Version] Journal of theAmerican Medical Informatics Association, 5(1). Retrieved January 14, 2002, from: http:// www.amia.org/pubs/ other/ email_guidelines.html.

American Psychological Association. (1997). APA statement on services by telephone, teleconferencing, and Internet. Retrieved January 14, 2002, from: http:// www.apa.org/ ethics/ stmnt01.html.

Barak, A. (1999). Psychological applications on the Internet: A discipline on the threshold of a new millennium. Applied and Preventive Psychology, 8, 231-246. Also available online: http://construct.haifa.ac.il/ -azy/app-r.htm.

Barak, A., \& Wander-Schwartz, M. (retrieved March, 2002). Empirical evaluation of brief group therapy through an Internet chat room. Available at: http:// construct.haifa.ac.il/ -azy/ cherapy.htm. 
Bennett, D., \& Fielding, P. (1999). The Net Effect: How cyber-advocacy is changing the political landscape. Merrifield, VA: E-Advocates Press.

Bloom, J.W. (February 1998). The ethical practice of Web Counseling. British Journal of Guidance and Counseling 26(1), 53-59.

Boland, K.M. (1998). Electronic advocacy: An introduction to the use of electronic techniques for social change. Boxboro, MA: New England Network for Child, Youth and Family Services. Retrieved February 12, 2002, from: http:// www.nenetwork.org/info-policy/ElecAdvo/index.html.

Buck, K. (1996). Community organizing and the Internet. Neighborhood Works. 19(2).

Burgoon, J.K., Buller, D.W., \& Woodall, W.G. (1989). Nonverbal communication: The unspoken dialogue. New York: Harper \& Row.

Cherny, L. (1995). The MUD register: Conversational modes of action in a text-based virtual reality. Unpublished doctoral dissertation, Stanford University Linguistics Department.

Clinical Social Work Federation (CSWF). (2001). CSWF position paper on Internet Text-Based Therapy. Retrieved November 11, 2001, from: http:// www.cswf.org/therapy.html.

Cohen, G., \& Kerr, B. (1998). Computer-Mediated Counseling: An empirical study of a new mental health treatment. Computers in Human Services, 15(4), 13-26.

Coleman, M. (2000). Online therapy and the clinical social worker. NASW Social Work Practice Update. Washington, DC: NASW.

Cutter, F. (1996). Virtual psychotherapy? Psychnews International, 1(3). Retrieved on March 1, 2002, from: http://www.psychnews.net/1_3/index.htm.

December, J. (1997, January). Notes on defining of Computer Mediated Communication. ComputerMediated Communication Magazine, 4(1). Retrieved January 26, 2002, from: http:// www.december.com/cmc/mag/ 1997/jan/december.html.

Downing, J., Fasano, R., Friedland, P., McCullough, M., Mizrahi, T., \& Shapiro, J. (1991). Computersfor social change and community organizing. Binghamton, New York: Haworth Press

Finn, J. (1995). Computer-based self-help groups: A new resource to supplement support groups. In M.J. Galinsky \& J.H. Schopler. (Eds.). Support groups: Current perspectives on theory and practice (pp. 109117). Binghamton, NY: Haworth Press.

Finn, J., \& Lavitt, M. (1994). Computer-based self-help for survivors of sexual abuse. Social Work with Groups, 17(1/2), 21-47.

FitzGerald, E., \& McNutt, J.G. (1999). Electronic advocacy in policy practice: A framework for teaching technologically based practice. Journal of Social Work Education, 35(3), 331-341.

Grohol, M.J. (1997). Theinsider's guideto mental health resources online New York: Guilford Press.

Guerrero, L.K., DeVito, J.A., \& Hecht, M. (eds.). (1999). The nonverbal communication reader. Prospect Heights, IL: Waveland.

International Society for Mental Health Counselors Online (ISMHCO). (January 9, 2000). ISMHO/PSI Suggested Principles for the OnlineProvision of Mental Health Services, [version 3.11]. Retrieved August 10, 2001, from: http://www.ismho.org/ suggestions.html.

Internet Healthcare Coalition. (2000). eHealth Code of Ethics. Retrieved on November 10, 2001, from: http:// www.ihealthcoalition.org/ethics/ehcode.html.

Kennard, W., \& Shilman, R.P. (1979). Group services with the homebound. Social Work, 24, 330-332.

King, S.A., \& Moreggi, D. (1998). Internet therapy and self-help groups-the pros and cons. In Psychology and the Internet: Intrapersonal, interpersonal, and transpersonal implications (pp. 77-109). San Diego, CA: Academic Press.

Lerner, H. (1990). Thedance of intimacy: A woman's guideto courageousacts of changein key relationships. London: Harper Collins.

Levenson, D. (1997). Online counseling: Opportunity and risk. NASW News. Sept. 1997, p. 3.

McNutt, J.G. (2000). Coming Perspectives in the Development of Electronic Advocacy for Social Policy Practice. Critical Social Work, 1(1). Retrieved on March 4, 2002, from: http://www.criticalsocialwork.com/00_1_coming_men.html. 
McNutt, J.G., \& Boland, K.M. (1999). Electronic advocacy by non-profit organization in social welfare policy. Non-profit and Voluntary Sector Quarterly, 28(4), 432-451.

McNutt, J.G., \& Boland, K.M. (1998). Teaching about advocacy and the Internet: Strategies for social welfare policy courses. Social Welfare Policy: The Newsletter of the Social Welfare Policy and Practice Group, 4(1), 3-6.

Meier, A. Galinsky, M.J., \& Rounds, K.A. (1995). Telephone support groups for caregivers of persons with AIDS. In M.J. Galinsky \&J.H. Schopler (Eds.). Support groups: Current perspectives on theory and practice (pp. 99-108). Binghamton, NY: Haworth Press.

Menon, G.M. (1998a) Legal issues of online counseling. Paper presented at WEBNET'98: 22 nd World Conference of the American Association for Computers in Education. Orlando, FL. November 7-12.

Menon, G.M. (1998b) “Wherewill I besued today?": Onlinecounseling and jurisdiction. Paper presented at the $2^{\text {nd }}$ Annual Conference on Information Technologies for Social Work Education and Practice. Charleston, South Carolina. August 16-23.

Menon, G.M. (2000a). therapy@socialwork.org?? IMHO v need 2 have guide---'s. Paper presented at the $18^{\text {th }}$ Annual Baccalaureate Program Directors Conference. Destin, FL. October 18-22.

Menon, G.M. (2000b). Online Counseling?? Should we do it? Paper presented at Social Work 2000: Strategies to succeed in the new market economy. Baltimore, MD. November 1-4.

Menon, G. (2000c). The 79-cent campaign: The use of on-line mailing lists for electronic advocacy. Journal of Community Practice. 8(3), 73-81.

Menon, G.M. (2001). Ethical and legal issues in the practice of onlinecounseling. Paper presented at the $3^{\text {rd }}$ International Conference on Social Work in Health and Mental Health. Tampere, Finland. July 1-5.

Menon, G.M., \& Miller-Cribbs, J. (2001). Guidelines for the effectivepractice of counseling online. HUSITA6 International Conference. Charleston, South Carolina. September 12-16.

Menon, G.M. (2002). Technology based groups and flash campaigns. In S. Hick and J. McNutt, (Eds.), Social work advocacy and community Organizing on the Internet. pp. 153-161. Chicago, IL: Lyceum Books.

Murphy, L.J., \& Mitchell, D.L. (1998). When writing helps to heal: e-mail as therapy. British Journal of Guidanceand Counselling, 26, 21-32.

National Board of Certified Counselors (NBCC). (November 3, 2001). The practice of internet counseling. Retrieved on October 18, 2002, from: http:// www.nbcc.org/ ethics/ webethics.htm).

Patterson, M.L. (1983) Nonverbal behavior: A functional perspective Springer Series in Social Psychology, Springer-Verlag: New York.

Patterson, M.L. (1990). Functions of non-verbal behavior in social interaction. In H. Giles, W.P. Robinson, and P. Robinson (Eds.), Handbook of Languageand Social Psychology, Hoboken, NJ: John Wiley \& Sons.

Powell, T. (1998). Online counseling: A profile and descriptive analysis. Retrieved on May 10, 2001, from: http://netpsychology.com/Powell.htm.

Roffman, R.A., Beadnell, B., Ryan, R., \& Downey, L. (1995). Telephone group counseling in reducing AIDS risk in gay and bisexual males. Journal of Gay and Lesbian Social Services, 2, 145-157.

Rounds, K.A., Galinsky, M.J., \& Stevens, L.S. (1991). Linking people with AIDS in rural communities: The telephone group. Social Work, 36, 13-18.

Sampson, J.P., Jr., Kolodinsky, R.W., \& Greeno, B.P. (1997). Counseling on the information highway: Future possibilities and potential problems. Journal of Counseling \& Development, 75, 203-218.

Shyne, A.W. (1954). Telephone interviews in casework. Social Casework, 35, 342-347.

Smyth, K.A., \& Harris, P.B. (1993). Using telecomputing to provide information and support to caregivers of persons with dementia. The Gerontologist, 33(1), 123-127.

Stofle, G. (1997). Thoughts about online psychotherapy: Ethical and practical considerations. Retrieved on February 12, 2002, from: http://members.aol.com.stofle/ onlinepsych.htm.

Stofle, G. (2001). Choosing an onlinetherapist: A step-by-step guideto finding professional help on theweb. Harrisburg, PA: White Hat Communications. 
Walker, J. (8/21/200). Cyber-Spying. Retrieved on March 2, 2002 from ABC NEWS.COM at: http://more.abcnews.go.com/onair/worldnewstonight/wnt000821_cyberspying_feature.html.

Walther, J. (1996). Computer-Mediated Communication: Impersonal, interpersonal and hyperpersonal interaction. Communication Research, 23, 3-43.

Weinberg, N., Uken, J., Schmale, J., \& Adamek, M. (1995). Computer-medicated support groups. Social Work with Groups, 17(4), 43-54.

Wiener, L.S., Spencer, E.D., Davidson, R., \& Fair, C. (1993). National telephone support groups: A new avenue toward psychosocial support for HIV-infected children and their families. Social Work with Groups, 16(3), 55-71.

\section{Some Sites of Interest}

- www.metanoia.org

- http://www.ismho.org/

- http:// www.rider.edu/ users/ suler/psycyber/psycyber.html

- http://netpsychology.com/

- http://members.aol.com/stofle/onlinepsych.htm

\section{Author's Note:}

Address correspondence to: Goutham M. Menon, Ph.D., Center for Technology in Social Work Education and Practice, College of Social Work, University of South Carolina, Columbia, SC 29208, USA. E-mail: goutham.menon@sc.edu. 